\title{
Human-dingo interactions on Fraser Island: an analysis of serious incident reports
}

\author{
Rob Appleby ${ }^{\mathrm{A}, \mathrm{C}}$, Jess Mackie ${ }^{\mathrm{A}}$, Bradley Smith $^{\mathrm{B}}$, Lilia Bernede $^{\mathrm{A}}$ and Darryl Jones ${ }^{\mathrm{A}}$ \\ AEnvironmental Futures Research Institute, Griffith School of Environment, Griffith University, \\ Nathan, Qld 4111, Australia. \\ ${ }^{B}$ Appleton Institute, School of Human Health and Social Sciences, Central Queensland University, \\ 44 Greenhill Road, Wayville, SA 5034, Australia. \\ ${ }^{\mathrm{C}}$ Corresponding author. Email: rob.appleby@wildspy.com.au
}

\begin{abstract}
Wild predators that attack people represent a significant challenge to the management authorities charged with conserving populations whilst minimising human safety risk. Fraser Island is home to an iconic population of dingoes (Canis dingo). However, conflict stemming from negative human-dingo interactions (incidents), some resulting in serious human injury and in one case, a fatality, is an ongoing concern. In an effort to highlight important factors influencing incident dynamics, we investigated the most serious incident reports gathered by the Queensland Parks and Wildlife Service for the period 2001-15. We found a consistent pattern of incidents peaking in March/April and also July, corresponding with dingo breeding and whelping seasons (respectively). Monthly vehicle permit numbers (a proxy for visitation) were not positively correlated with incident rates, except during the breeding season. Male dingoes, particularly subadult males, featured heavily in incidents. Despite the fatality being highly publicised and the advent of copious on-site warning messages and other management interventions, serious incidents continue to occur annually, including some involving children. This suggests that risks are either not always understood, or are otherwise being ignored. While our results demonstrate that dingoes generally pose minimal risk to humans, some risk remains, particularly where poorly supervised children are concerned.
\end{abstract}

Additional keyword: human-wildlife interaction.

Received 27 May 2016, accepted 31 May 2017, published online dd mmm yyyy

\section{Introduction}

Attacks on people by wild animals are rare, but they attract a great deal of media and public attention (Conover 2001; Penteriani et al. 2016). More generally, human-wildlife conflict appears

5 to be on the rise (Conover 2001; Penteriani et al. 2016). At the same time, there has been a push in recent decades to conserve some potentially dangerous predators (Schmidt and Timm 2007; Appleby 2015a), resulting in a shift towards more non-lethal strategies to manage conflict (Reiter et al. 1999; Gilsdorf et al.

10 2002; Massei et al. 2010). However, where human safety is a major concern, the general public may remain tolerant of lethal control (Reiter et al. 1999). In this sense, attacks by wild predators can hinder conservation efforts (Dalton 2004). Increasing predator populations may have some bearing on

15 attacks, but a recent review also flagged human factors, such as an increase in people engaging in recreational activities outdoors, and an exhibition of what was labelled as riskenhancing behaviours on the part of people, contributing markedly to attacks (Penteriani et al. 2016). In particular, poor

20 supervision of children appeared to be commonly correlated with attacks (Penteriani et al. 2016), as has been noted elsewhere in more specific circumstances (Beier 1991; Rajpurohit 1999; EPA/QPWS 2006; Appleby 2015a).

Several studies have closely examined data associated with particular terrestrial species attacking humans. Perhaps the longest-running database of terrestrial predator attacks involves the three species of North American bear (Ursus spp.) (Herrero 1970, 2002; Herrero and Fleck 1990; Herrero and Higgins 1999, 2003; Herrero et al. 2011). Other predators such as large felids feature in attacks on humans, with a review by Inskip and Zimmermann (2009) suggesting that in some locations attacks are in decline, possibly because of declining felid populations, whilst in other areas, attacks continue to rise. Several comprehensive reviews have also been undertaken in relation to wild canids implicated in attacks. Both Linnell et al. (2002) and McNay (2002) examined available historical records pertaining to attacks by grey wolves (Canis lupus), the former across the range of the species, and the latter focussed on North America. More recently, White and Gehrt (2009) examined newspaper records, agency records, and previous reviews (Carbyn 1989; Timm et al. 2004) of coyote (Canis latrans) 20 attacks for all of North America for the period 1960-2006. 
A good deal of the impetus for analysing incidents is in an effort to discern credible reasons for them to have occurred, so that, in turn, they might be better avoided or mitigated in management programs in the future (Penteriani et al. 2016). A 5 commonly cited causal factor in relation to wildlife attacks is 'habituation', where it is usually taken to mean a loss of fear of human beings on the part of the animals involved (McCullough 1982; Fleming et al. 2001; Linnell et al. 2002; McNay 2002; Timm et al. 2004; White and Gehrt 2009; Geist 2011). Another

10 commonly cited reason for attacks is food conditioning (McCullough 1982; Peine 2001; Mazur 2010). Hopkins et al. (2010: 157) defined a food-conditioned bear as one that '.. has learned to associate people (or the smell of people), human activities, human-use areas, or food storage receptacles with

15 anthropogenic food'. This definition can theoretically be extended to many other species.

However, the roles that habituation and anthropogenic feeding play in attacks remain controversial (Schmidt and Timm 2007; Appleby 2015a), and there can be considerable confusion in the

20 literature in relation to these terms despite their being distinct from one another (Whittaker and Knight 1998; Hopkins et al. 2010; Appleby 2015a). A possible route to an attack involving food is where an animal has learned that by being aggressive towards people it can secure food from them, which might be

25 thought of as reinforced or conditioned aggression. Herrero et al. (2011) speculated that some black bears, for example, may become increasingly aggressive in attempts to secure anthropogenic food, and may be more likely to injure or kill people as a result. How common such a phenomenon is in other

30 species is difficult to ascertain. The role of habituation is arguably more contentious, with debate about its role in predicating bear attacks having considerable support both for (McCullough 1982; Geist 2011) and against (Jope 1985; Rogers and Mansfield 2011) the idea.

A plethora of other factors that may be contributing to negative human-wildlife interaction dynamics have also been suggested. In North America, for example, Herrero et al. (2011) discussed many major factors that may contribute in some way to, or correlate with, black bear attacks, including the sizes and growth

40 of bear and human populations over recent decades, the number of people present (most attacks involved 1-2 people), the sex of bears (males were implicated in $92 \%$ of cases), the time of year ( $85 \%$ of attacks occurred between May and September) and concluded that most attacks were motivated by predation. The

45 latter is of obvious concern and has been suggested as a motivation for attacks, particularly in relation to those involving children, by other species including wild canids such as wolves (Linnell et al. 2002, 2003; McNay 2002) and coyotes (Carbyn 1989; Timm et al. 2004; Schmidt and Timm 2007; White and

50 Gehrt 2009).

In Australia, a related canid, the Australian dingo (Canis dingo) has featured in conflict with people, historically more because of attacks on livestock (Breckwoldt 1988; Allen and Sparkes 2001; Corbett 2001; Fleming et al. 2001; Allen and West

55 2013; Appleby 2015b) but more recently because of attacks on humans (Corbett 2001; Fleming et al. 2001; Appleby 2015a). Two very high profile cases featured the fatalities of children, the first of which went on to become one of the most famous legal sagas in Australian history, and involved the death of
Azaria Chamberlain at Uluru in 1980. The second occurred on Fraser Island 21 years later and involved the death of a nine-yearold boy. The latter was the impetus for a major reappraisal of dingo management on the island, currently thought to comprise a population of $~ 130$ dingoes (range: 104-194: Appleby and Jones 2011), and resulted in an almost immediate cull of 31 individuals (Thompson et al. 2003). Destructions had risen to 110 dingoes by the end of 2012 (Allen et al. 2015). The conservation importance of the Fraser Island dingo has been widely recognised (Corbett 2001; Burns and Howard 2003; Hytten and Burns 2007; DEHP 2013; Allen et al. 2015; Smith and Appleby 2015; O'Neill et al. 2017); however, ongoing serious incidents, and a shortage of viable management alternatives, has meant that lethal control remains a management mainstay.

As is the case with other species, there may be many reasons why such incidents occur. The original Fraser Island Dingo Management Strategy (EPA/QPWS 2001) makes reference to a suite of factors that may be directly or indirectly associated with incidents. These include both human- and dingo-specific factors (as well as interplay between these factors), that managers make concerted efforts to tackle. Similar to situations elsewhere, habituation and anthropogenic feeding are proposed as a common denominator (Fleming et al. 2001; Allen et al. 2015). Appleby (2015a) argued that whilst habituation, and particularly feeding, may set the stage for incidents to occur, unless conditioned aggression is a salient feature, there are steps missing in our understanding of what leads to aggressive or threatening encounters. Predation (mostly directed at children) has also been suggested as a motivation on the part of dingoes (Corbett 1998; Fleming et al. 2001), as has play (Corbett 1998; Allen et al. 2012; Allen et al. 2015; Appleby 2015a).

Here we present a summary of data collected by the Queensland Parks and Wildlife Service (QPWS) pertaining to the most serious dingo incident reports on Fraser Island (a total of 160 reports from 2001-15). We expand on previous summaries including an early examination (Appleby et al. 2004), a more recent summary provided as part of an overall review of the dingo management strategy on the island (Allen et al. 2012), and another as part of a discussion on the impacts of lethal control (Allen et al. 2015). Because the available data were not suitable for a more in-depth statistical analysis, we did not set out to specifically attribute a cause or causes to incidents directly, either on the part of dingoes or people involved, or in relation to other variables. Instead, we used an exploratory approach in order to develop plausible suggestions for the occurrence of incidents. This included an attempt to ascertain the salient variables featured in reported incidents; from our results, we offer some considerations in relation to potential drivers of incident dynamics and we broach ideas for future research in this regard.

\section{Methods}

Study site

Fraser Island is located $288 \mathrm{~km}$ north of Brisbane, the capital city of Queensland, Australia. At $123 \mathrm{~km}$ long and $165280 \mathrm{ha}$, it is the world's largest sand island, and was inscribed on the World Heritage List in 1992. Some 400000 people visit the

45 
island each year (Allen et al. 2015). Allen et al. (2015) (see also Allen et al. 2012) note, however, that visitor numbers are imprecise so it is unclear if, or to what degree, visitation rates fluctuate.

\section{Dataset}

The QPWS provided us with an archive of dingo incident report forms, many of which are the product of voluntary submission by visitors, spanning 2001-15. Thus, our results should be interpreted in relation to rates of incident reporting, rather than

10 overall rates of actual incidents, with a caveat that some incidents may go unreported. Interaction reports are categorised from A to $\mathrm{E}$; however, categories A and B mostly pertain to sightings or benign interactions. Incident categories range from $\mathrm{C}$, the least serious, to E, the most serious (Allen et al. 2012). We focussed

15 only on the most serious incidents (Category E) because these are of the greatest management concern and are probably the most consistently reported type of incident. Reports were provided in one of two formats: either as PDF documents of scanned hardcopy incident reports, or as summaries in Excel spreadsheets.

20 We examined scanned PDF records in detail and collated a new database of variables from the information available. The incidents included in this analysis were reported from March 2001 to September 2015 ( $\sim 15$ years). We were limited by the degree of information available for records before 2011, as scanned reports

25 dating back from that year often did not contain a consistent level of detail. As such, only basic analyses were possible for the period 2001-11, while more comprehensive analyses were possible for the period 2011-15.

For each incident report, we attempted to extract information 30 grouped into the general categories of: time, space, dingo factors, human factors and, where possible, relationships between groups of variables.

\section{Variable descriptions}

\section{Temporal factors}

35 We extracted the date of an incident and categorised this into day, month and year and classified the time of incident into day (0500-1659 hours) and night (1700-0459 hours).

\section{Spatial factors}

The location of incidents was included in all reports, and when 40 specific sites were recorded we classified these according to their distance to the nearest well known location (approximate location), which were typically within $5 \mathrm{~km}$ of the location described in the incident report. We also classified incidents by a general location including: beach (incidents occurring on the

45 beach or on the immediate sand dunes at the beach perimeter), campsite (incidents occurring in campsites), and elsewhere (incidents occurring at a lake, on tracks, bush, boardwalk, township or resort). We were conservative in our classification and if explicit information was unavailable a record was 50 marked N/A.

\section{Dingo-related factors}

There was insufficient information to attribute a particular motivation for the behaviour of dingoes during incidents. Instead, we simply classified an incident type as the most severe behaviour listed on an incident report as being exhibited by the dingo(es) during the incident. The behaviours listed were as follows: stalk, nip, lunge, loitering, hunting tactics, herding, growl, dominance, circling, chasing, bite and death. In the bite category, we classified the severity of the bite as: puncture wound injuries that did not require hospitalisation, injuries where one area was bitten and required hospitalisation, and incidents where two or more areas were bitten and hospitalisation was required. We grouped these results under the variable 'dingo behaviour'.

We used the month of incident data to group incidents into dingo seasons, following the information provided by QPWS (2015) and Smith (2015): independence (December-February), breeding (March-May), whelping (June-August) and weaning (September-November). Independence was classified as the period when young dingoes are largely no longer expected to be reliant upon parental care. We kept these periods static because more specific information was absent, but, in reality, some variation would be expected year to year and across the island.

Some dingoes on Fraser Island are captured and tagged as part of ongoing management practices. Generally, tags feature coloured strips aimed at aiding visitors and staff in their identification. Additional information about dingo identity can usually be gleaned from observations (e.g. right or left ear denotes sex; button position denotes northern or southern districts; scars or other visible markings; size, etc.). Using a combination of such information, QPWS staff are often able to accurately identify dingoes for management purposes (Appleby and Jones 2011), including incident reporting. More information on tagging and related information such as the aging of dingoes by QPWS staff on Fraser Island can be found in Behrendorff and Allen (2016). The tag identification of dingoes was included in $48 \%$ (76 of 160 ) of incident reports, and, where missing, was ascribed N/A. However, not all dingoes are tagged so N/A does not necessarily imply 'not tagged'. When the age and sex of the dingoes was provided, we included it in our summary; however, this variable was again often missing. Wherever possible, we extracted counts of dingo group size and dingoes present but not involved in the incident from the incident descriptions. As with all data, those involving dingo factors were taken at face value and were assumed to be correct unless an error (e.g. typo) could be explicitly determined.

\section{Human-related factors}

The medical outcome of the incident was characterised by the injury information provided in the incident reports and was noted as unknown when no information was available. For ease of analysis, we grouped the injuries into: unknown, injury (minor mark/scratch and no medical attention), medical (medical attention required) and hospitalisation (admitted to hospital). We did not assume that an absence of injury records meant an absence of injury, but we recognise that this is possible. Depending on the detail of the incident descriptions provided, we attempted to determine what kind of activity people were engaged in before an incident. Some examples included walking, running, fishing and feeding dingoes. Where information was unavailable, N/A was recorded. We also attempted to determine whether people were alone or not.

In some cases, a review of the incident descriptions allowed us to determine whether children were present, and we classified 
a child as anyone aged 12 years old or younger. Where possible, we derived the distance of an adult from a child as being either very close (an adult being $\sim 5 \mathrm{~m}$ or less from a child) or not very close where it was clearly stated in the reports. A distance of $5 \mathrm{~m}$

5 or less was chosen as being representative of the highest possible level of vigilance and fastest reaction distance on the part of adults. Many reports had little-to-no pertinent information in this regard and were marked as N/A.

Data approximating visitor numbers, in the form of vehicle

10 access permits provided by QPWS, were compiled from online records (at https://data.qld.gov.au/dataset/camping-and-vehiclepermits, accessed 30 November 2016). Available records closely matched a portion of the incident reporting period including all camping and vehicle access permits granted by QPWS from

15 January 2011 to December 2015. Vehicle permits were chosen as a proxy for visitor numbers over camping permits, as the latter only represents an unknown proportion of total visitors to the island, and whilst this is also true to some extent in relation to vehicle permits (i.e. not all visitors have vehicles) it was

20 considered likely that discrepancies would be fewer in number compared with those in relation to camping permits. There was also no way to distinguish between the users of each permit type, so only one or the other could be chosen, in order to avoid doubling up. Pertinent data for Fraser Island were extracted and collated in preparation for inclusion in the analyses.

Monthly mean vehicle permit numbers were pooled across the available period (2011-15). Dates of visitation were taken as the date that a one-month vehicle permit was granted. Permits relating to the only other type of vehicle permit available

30 (12-month) were not included because these were markedly fewer in number, as they are generally provided to island residents or staff.

\section{Relationships between variables}

We examined certain relationships between variables that

35 appeared to be of potential interest. For example, we looked closely at subadult male dingoes, examining incidents for this subgroup by time and space, as well as other variables. When investigating the sex by age class of dingoes involved in incidents throughout the year, we used 15 July as an arbitrary

40 line where juveniles become subadults. In reality, this date may vary if the dingoes' date of birth is known year to year; however, we used this as a constant demarcation. We also examined pertinent spatiotemporal factors wherever possible.

\section{Statistical analysis}

45 Our analyses were largely exploratory rather than confirmatory (Martin and Bateson 1986), with our aim being to produce a credible summary of the data. We did this to highlight possible points of interest in relation to incident dynamics. As the incident reports contained varying amounts of information for level of analysis and, where pertinent, this is noted. Percentages were rounded up to the nearest whole number. Where required for disambiguation, an upper-case ' $N$ ' denotes the total number of incident reports to which a given result refers (i.e. this was not always the maximum of 160 incident reports), whilst a lower-case 'n' denotes the actual proportion of the total or else the specific number of replicates. Otherwise, both the proportion and resulting percentage are provided. Basic descriptive approaches were undertaken in Microsoft Excel ${ }^{\circledR}$ (2010) and Pearson's correlations and a simple linear regression were undertaken in the R 2.1.5.2 statistical environment.

\section{Results \\ Temporal factors}

Category E records $(n=160)$ were available for all years over the 15-year period (2001-15), with a mean of 10.7 reports per year $(\mathrm{s} . \mathrm{d} .=6.39$, range $=3-22,95 \% \mathrm{CI}= \pm 3.54)$.

The highest tally for a given year was 22 incidents in 2004, whilst the lowest tally of 3 incidents occurred in 2007. Available vehicle permit records were limited to the period 2011-15, with a consistent rise from 31586 permits in 2011 to 38238 permits in 2015.

There was only a relatively weak and non-significant positive trend in incident frequency across years $\left(r^{2}=0.09, P=0.28\right)$. In total, $73 \%(n=117)$ of reported incidents occurred in daylight hours and $27 \%(n=43)$ occurred at night.

When pooled across all years, there was, on average, 13.3 incident reports per month (s.d. $=7.31$, range $=3-22,95 \%$ $\mathrm{CI}= \pm 4.65, n=12$ months). However, as Fig. 1 shows, monthly incidents exhibit a strong seasonal trend, with $44 \%$ of the 160 records occurring in March (13\%), April (18\%) and July (13\%), all three months together making 44\%. This corresponds with the dingo breeding season but may also reflect increases in visitation linked to school holidays.

In contrast to the apparent dingo seasonal influence on incidents, no correlation was found between pooled monthly incident reports and pooled monthly vehicle permit numbers ( $r=-0.04, P=0.8908$ ), suggesting that little of the variation is explained by monthly visitor numbers. Looking at Fig. 1, however, there does appear to be an association between monthly visitor numbers and monthly incident reports in the early months of the year, with comparable spikes around April. In the latter half of the year, there is no obvious relationship. Incident reports appear to peak in April and reach a low around November each year, with vehicle numbers reaching a peak in September and a low around February. An additional spike in incident reports occurs around July each year, which corresponds to the dingo whelping period and another school holiday period, but vehicle permit numbers do not correspondingly spike.

\section{Spatial factors}

Incidents took place in a total of 23 approximate locations across the island (see Fig. 2).

Most incidents occurred on or near eastern beach locations, with two prominent, geographic clusters of incidents, one from Eurong to Lake Wabby, and the other from Yidney Rocks to Cathedral Beach.

In total, $27 \%$ (43 of 160) of reported incidents took place at Eurong. Following Eurong, were Kingfisher Bay Resort and Village (KBRV) with 9\% (15 of 160) of incidents, and Coolooloi/ Hook point and K' Gari, both with 8\% (13 of 160) of incidents each. The average number of reported incidents across all 23 locations was 6.96 (s.d. $=9.0$, range $=1-43,95 \% \mathrm{CI}= \pm 3.87$, $n=23$ locations). 


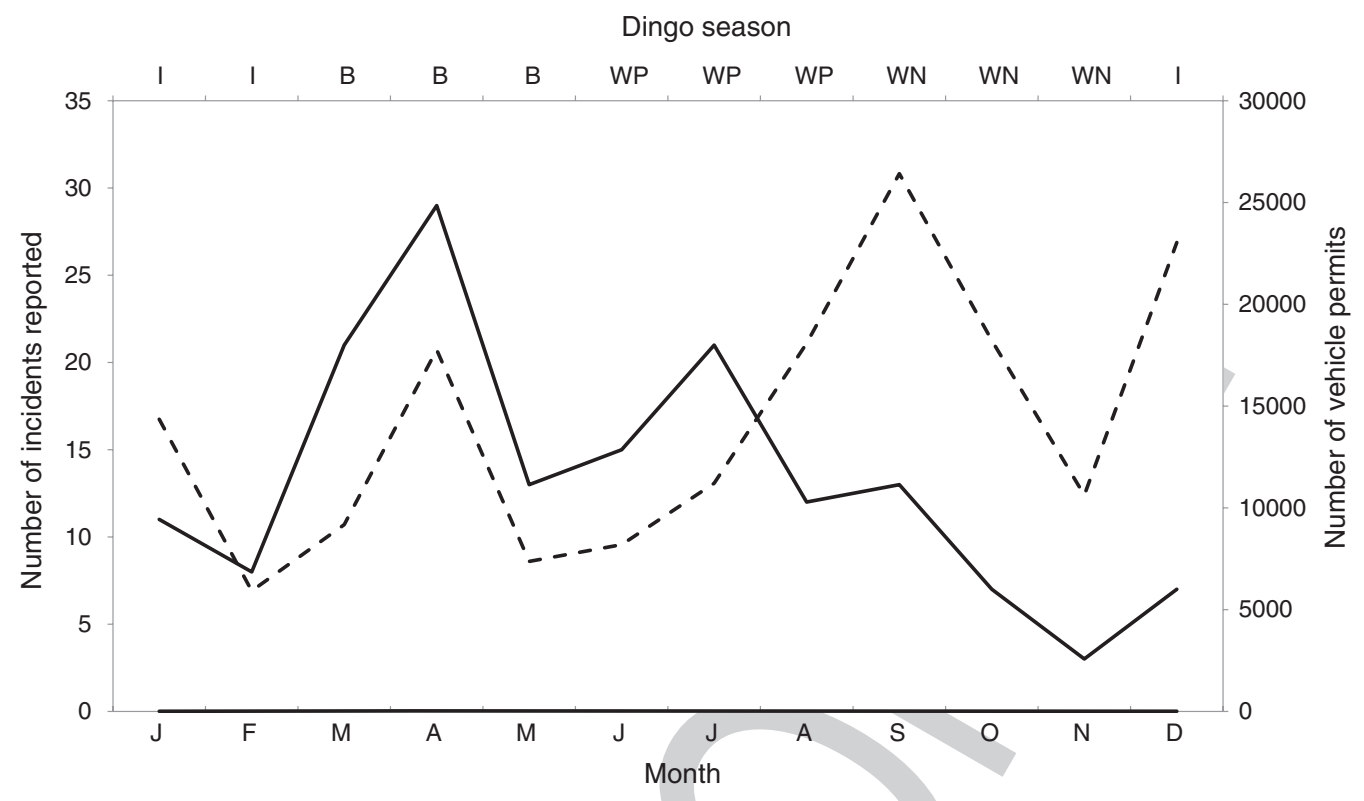

Fig. 1. The total number of monthly Category E incidents (solid line, $n=160$ ) and the total number of monthly vehicle permits (dashed line), pooled across years. The corresponding portion of the dingo season is indicated along the top axis, where: I, independence; B, breeding; WP, whelping; Wn, weaning (see Smith 2015).

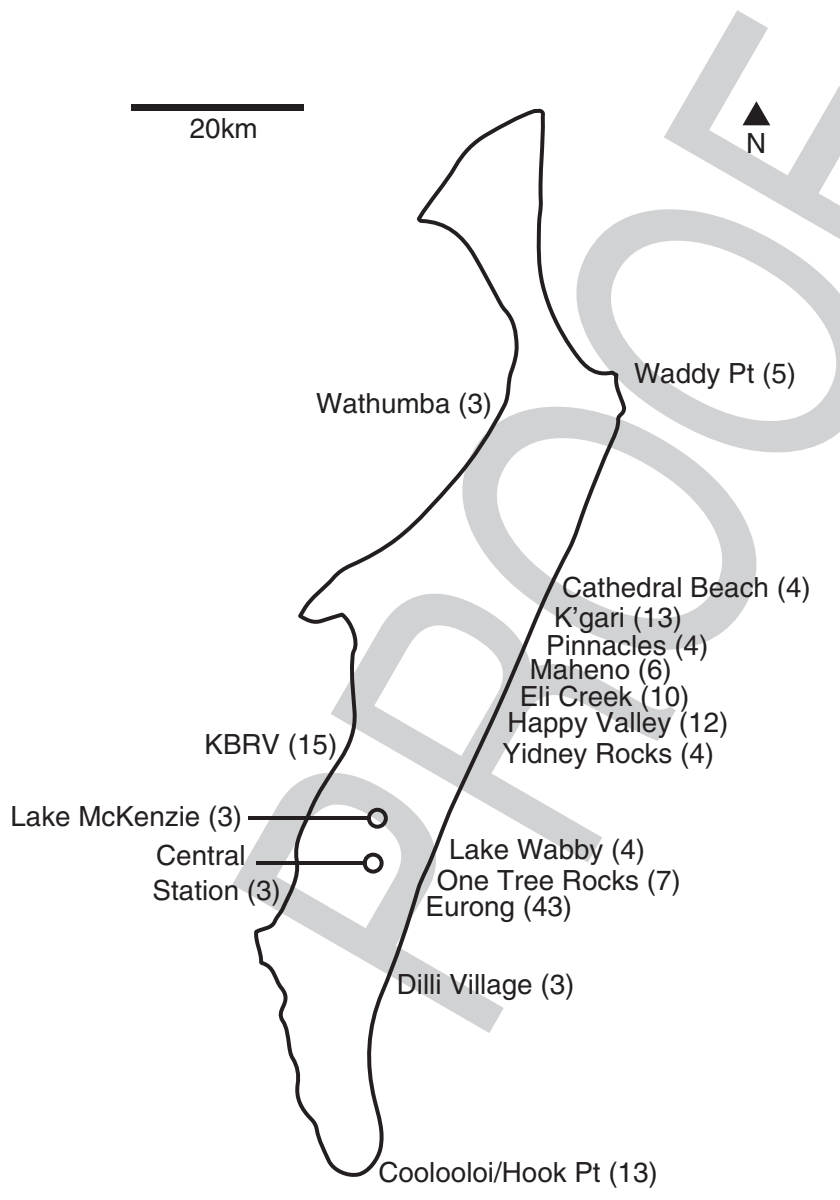

Fig. 2. Map of Fraser Island illustrating approximate locations and incident number in parentheses. Only locations with three or more incident reports are included.
In $26 \%$ of incidents (42 of 160) no detailed information was provided on the location type (e.g. beach, campground). Of the remainder $(n=118), 64 \%$ occurred on or close to a beach, $12 \%$ in campsites, and $25 \%$ occurred in diverse locations (e.g. lakes, tracks, bush, boardwalk, township, resort). Most reported 5 incidents in Happy Valley $(83 \%, n=12)$ and Eurong $(63 \%$, $n=43$ ) occurred on the beach.

\section{Spatiotemporal interaction}

For seven years of the 15-year reporting period, Eurong had the highest number of incidents reported compared with all other locations. At Eurong, incidents occurred consecutively every year with the exception of 2002, 2003 and 2012. Of the 43 incidents recorded there, April (19\%) and June (16\%) yielded the highest numbers respectively, followed by July (12\%) and September (9\%) incidents. Although KBRV recorded the second highest number of incidents for a single location, there were no Category E incidents reported after 2004.

\section{Dingo-related factors}

Of the 94 incident reports where sex was recorded, $81 \%(n=76)$ were male dingoes and 19\% $(n=18)$ were females. Of the 108 incidents where age-class was stated, subadults $(47 \% ; n=51)$ and juveniles $(31 \% ; n=33)$ featured more commonly than adults $(22 \% ; n=24)$. In 90 incidents in which both sex and ageclass were determined (Fig. 3), there was a clear bias in male representation: subadults ( $n=45: 93 \%$ male versus $7 \%$ female), juveniles ( $n=27: 67 . \%$ male versus $33 . \%$ female) and adults ( $n=18 ; 67 . \%$ male versus $33 . \%$ female).

When grouping months according to the four 'dingo seasons', $39 \%(n=63)$ of all incidents occurred in the breeding season (March-May), peaking in April and 30\% $(n=48)$ in the whelping 


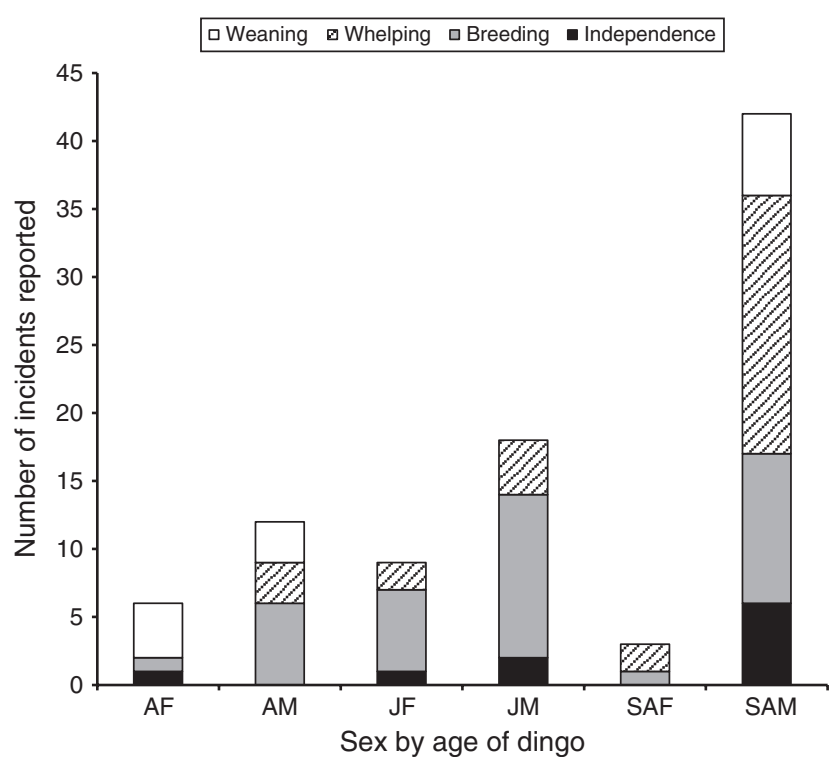

Fig. 3. Category E incident report frequency of known dingo sex-by-age class and dingo season $(n=90)$. AF, adult female; AM, adult male; JF, juvenile female; JM, juvenile male; SAF, subadult female; SAM, subadult male.

season, peaking in July (Fig. 1). Serious incident reports reduced by more than half in the whelping $(14 \% ; n=23)$ and independence $(16 \% ; n=26)$ seasons when compared with the breeding season.

Fig. 3 shows the frequency of incidents for the interaction between dingo sex by age class $(n=90)$ and dingo season.

Of the 37 incidents that occurred during the breeding season, it was juvenile male dingoes that featured the most frequently $(32 \%)$. Subadult males were involved in the highest number of

10 incidents during all other seasons. Females of all age classes were infrequently involved in incidents.

Amongst all incidents reported $(n=160), 48 \% \quad(n=77)$ featured tagged dingoes with the tag ID recorded. These reports involved 40 different dingoes, which, on average, were involved

15 in 1.9 attacks each (s.d. $=1.08$, range $=1-5,95 \% \mathrm{CI}= \pm 0.35$, $n=40$ ). In total, 20 tagged individuals were each involved in a single incident, nine in two incidents, seven in three incidents and three tagged individuals were involved in four incidents. One individual (a juvenile male) was involved in five incidents,

20 the highest number of Category $\mathrm{E}$ incidents recorded for any individual, all of which occurred in 2012 at Cathedral Beach, K'Gari and the Maheno (the dingo was destroyed on 22 November 2012: QPWS, unpubl. data). There is likely to be some overlap each year in terms of individuals featuring as 25 both juveniles and subadults, or subadults and adults.

Of all incidents $(n=160)$, most involved a solitary dingo $(78 \%, n=124)$, with a further $11 \%(n=18)$ involving two dingoes, $5 \%(n=8)$ involving three dingoes and the remaining $6 \%(n=9)$ involving four or five dingoes. An additional incident

30 in 2009 involved 12 dingoes, the highest number recorded for a single incident.

Given the number of subadult males involved in incidents, we examined these incidents further. Of the 90 incidents for which sex and age of dingo was reported, subadult males

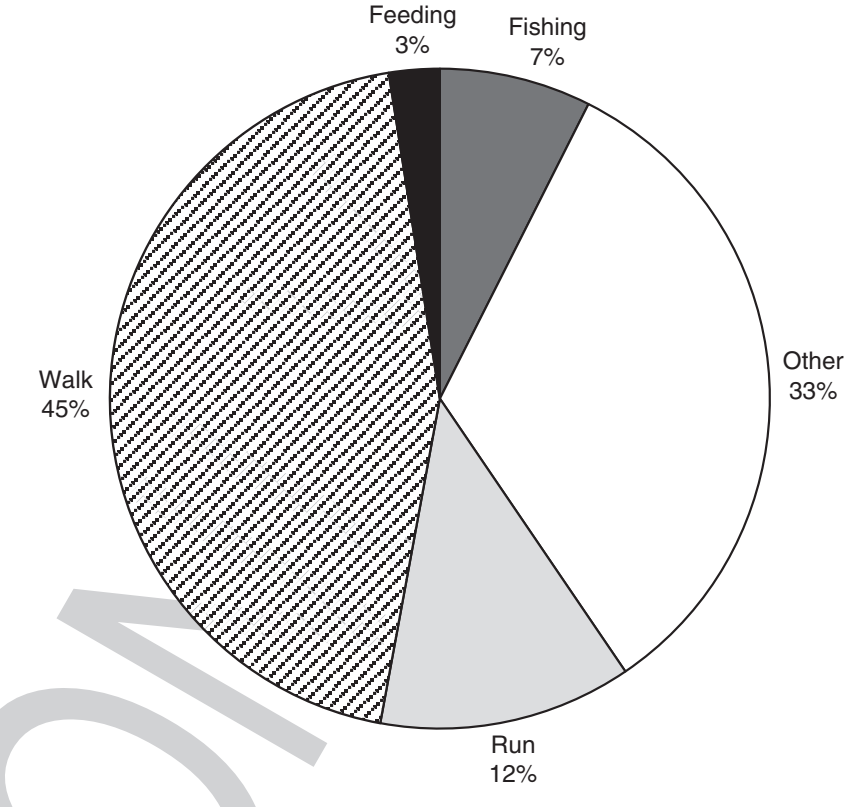

Fig. 4. Human activity before an incident, expressed as a percentage of reported incidents. Note: this was according to self-reported activities listed $(n=121)$.

featured in $47 \%(n=42)$ of cases compared with $3 \%(n=3)$ involving females. No incidents involving subadults were listed before 2004; however, most incidents in this period involved dingoes of unknown sex and age (18 of 20). Of 39 incidents involving subadult males, $85 \%(n=33)$ occurred during the day. Nipping was the most common dingo behaviour reported (17 of $42,40 \%$ ), followed by lunging (10 of 42, 24\%) and biting (9 of 42, 21\%). Exactly half of all incidents featuring subadults involved people either walking or running. Subadult male dingoes were involved in 37\% (24 of 66) of all incidents where a minor injury was reported but 30 cases of injury involved dingoes of unknown-age so this may represent a minimum. One incident involving a subadult male dingo resulted in medical attention being required and one required hospitalisation. The medical outcomes of the remaining incidents involving subadult males were unknown.

\section{Human-related factors}

Fig. 4 presents a summary of all cases where human activity immediately before an incident was recorded.

Approximately $45 \%(n=54)$ of incidents with a stated human activity immediately before an incident $(n=121)$ occurred while people were walking, and a further $12 \%(n=15)$ while running. The category 'other' included: cooking/eating, playing, sleeping, swimming, taking photographs and washing hands/face in surf, and accounted for 33\% $(n=40)$ of incidents. Fishing was listed in $7 \%(n=9)$ of incidents, and in $3 \%(n=3)$ of incidents people were reported to have been feeding dingoes.

We were unable to determine whether people involved in $50 \%(n=80)$ of all available incidents sought or needed medical attention. Whilst this may simply have been because no injury occurred, we did not assume this to be the case. In the remaining 80 cases, $82.5 \%(n=66)$ were listed as a person having sustained 
a minor injury, $10 \%(n=8)$ required medical attention (e.g. first aid), $6 \%(n=5)$ required hospitalisation and one incident resulted in a death, which occurred in April 2001 (see Appleby $2015 a$ for further details).

In 58 cases both activity and medical outcome were recorded. Minor injuries accounted for $76 \%(n=44)$ of records, with activities for this level of injury subdivided into walking $(34 \%$; $n=15)$, running $(7 \% ; n=3)$ and fishing $(7 \% ; n=3)$. More than half $(52 \% ; n=23)$ of the incidents grouped into a variety of 'other'

10 activities (see above). Of the $14(24 \%$,) remaining incidents, which involved more extensive injuries, walking and running preceded the attacks in all but one case.

Of the total incidents reported $(n=160)$ we determined that a person was alone in $40 \%(n=64)$ of cases and not alone in $36 \%$

$15(n=58)$ of cases. Accurate information on human group size of the remaining incidents $(n=38)$ was unavailable.

Of the 160 recorded Category $\mathrm{E}$ incidents, $23 \%(n=36)$ involved children being present or directly involved. Of these, $39 \%$ (14 of 36) cases listed a medical outcome. Death,

20 hospitalisation and medical attention occurred in one incident each, and 11 incidents resulted in minor injuries to children. Of the incidents involving children, we were able to determine that adults were present in $89 \%(n=32)$ cases (this does not necessarily mean that adults were not present in the four

25 remaining cases, only that this was not recorded). In 53\% (17 of 32) of these cases adults were very close to children, while in the remaining $47 \%$ (15 of 32) of cases adults were further away. Minor injuries to children occurred both in cases where adults were listed as very close $(45 \%, 5$ of 11$)$ and not as close $(27 \%$,

303 of 11), the remainder being unspecified. However, the three most serious incidents reported, including a death, involved adults being further away than $5 \mathrm{~m}$.

\section{Discussion}

Time and space

35 There was no clear trend in incidents across the entire reporting period, with reported incidents appearing to fluctuate over the years and no discernible correlation between reported incidents and year of reporting. Therefore, there is no indication that incidents have either linearly risen or fallen over the

40 reporting period and overall the reporting rates appear to have remained similar. An exception appears in the years 2005-08, when incidents reached a reasonably consistent low point, the reasons for which are not clear.

Pooled monthly peaks in incident reports corresponded with

45 the breeding and whelping seasons, a trend that remained consistent over the reporting period, as has previously been observed (Allen et al. 2012; Appleby 2015a). The Easter school holiday period occurs in March or April of each year and sees an influx of tourists and visitors to the island (Appleby 2015a),

50 further corroborated by the moderate spike in vehicle permits granted at that time of year. The July spike in incident reports also coincides with a major school holiday period, again, reflected somewhat in the vehicle permit data. Yet holiday periods, and the associated increase in human visitation also

55 occur at other times of year (e.g. September, when vehicle permits reach their annual peak, as well as the Christmas break over December-January) when reported incidents are amongst their lowest. Therefore, although there is potentially a link between incident reports, specific dingo seasons and periods of high human visitation (e.g. in April each year), the relationship between visitor numbers and incident rates more generally is unclear. This is partly due to the records relating to visitor numbers being inconsistent (Allen et al. 2012). A positive note is that despite visitor numbers increasing over the available period (2011-15), no similar rise in reported incidents was apparent, with incidents appearing to steadily decrease over the same period. More accurate records and clearer visitor numbers may reveal robust trends and any associated, potential correlation with incident reports. Examining potential relationships between incident reports and visitor numbers therefore remains an important knowledge gap deserving of re-evaluation.

Examining records in regard to prominent locations across years was revealing. For example, Eurong maintained the highest annual record of serious incidents in all but three years. This includes years following the construction of a fence around a resort and township designed to reduce dingoes interacting with people within such areas. A previous review found that there was no overall significant difference between the number of incidents occurring before and after fence construction at Eurong (Allen et al. 2012). Of note was that no Category $\mathrm{D}$ or $\mathrm{E}$ incidents were recorded inside the fenced areas (Allen et al. 2012). At KBRV, following the construction of a dingo-exclusion fence in 2004/05, we found that no further serious incidents were recorded at or near the resort, inside or outside the fenced areas. Viable fences are likely to reduce or eliminate the prospect of incidents occurring inside fenced areas. However, if encounters can occur outside of fenced areas, incidents can also occur. The difference between Eurong and KBRV is therefore probably not the effectiveness of fences per se, but more the prospect of incidents occurring outside fenced areas.

The clustering of incidents around a few beach locations suggests that very few dingo packs consisting of individuals tolerant of close human presence might be involved in most incidents. These sections of beach are very popular with people all year round, and, as such, encounters with dingoes may occur more frequently. Concentrating management effort to modify dingo and human behaviour in these particular areas offers considerable opportunity to reduce interactions and subsequent incidents. However, it is not necessarily clear why more encounters might lead to more incidents per se, so other factors require exploration.

\section{Dingo-related variables}

Male dingoes were involved in most reported incidents and male subadult dingoes were the highest single sex-by-age category featured. Sex-related differences have not been discussed in the literature concerning incidents involving other wild canids. However, Herrero et al. (2011) found that male black bears were heavily featured in attacks on humans and flagged some sex-related differences as potential, underlying reasons. They noted that males require considerable nutritional resources in preparation for their competition for mates (Herrero et al. 2011). In turn, this might lead males to takes greater risks to secure food. Herrero et al. (2011) concluded that predation was the major motivation for attacks on humans by black bears. While 
there may be a similar explanation behind male dingoes being disproportionally involved in incidents, the bias that we found towards young males in particular suggests that other possibilities rather than predation are worth discussing.

For example, juvenile males featured most prominently during the breeding season. Subadult males featured most prominently at all other times, including in the whelping season a few months later. This is almost certainly the same cohort of males transitioning from being juveniles in March/April to

10 subadulthood in July, because the previously labelled subadults would have transitioned into adulthood at around the same time. Juvenile males may be capable of breeding in some circumstances (Corbett 2001; Smith 2015), but how competitive they might be as potential breeders, and to what degree this

15 might prompt engagement in incidents is unknown. Adult males, who probably are more fervent in their competition for mates, were proportionally involved in more incidents in the breeding season compared with other seasons. However, their involvement in incidents was still relatively rare across the reporting period.

20 Corbett $(1998,2001)$ described domestic calves becoming 'frisky' when encountered by dingoes during the dingo breeding season. Dingoes would subsequently pursue and attack calves and Corbett (2001) felt this might have been due to hormonal changes in dingoes stemming from intermale competition and

25 redirected aggression. For instance, Smith et al. (2016) found that males exhibited greater levels of stress hormones in the breeding season in a captive population. An examination of hormonal assays between the different sex-by-age classes at different times of the year on Fraser Island may therefore be 30 illuminating in relation to incident dynamics.

\section{Food stress}

As dingoes are seasonal breeders, any competition relating to mating would largely conclude at the end of April/May, but before pups are born in June/July. Whilst competition relating

35 to mating cannot be a factor for incidents occurring in the whelping season, there are mechanisms relating to food stress (Carbyn 1989) that could potentially contribute. New-born pups add to the nutritional burden of social groups, such that mothers and alloparental carers probably need to seek a wider array of

40 food sources in an effort to provide for pups and mothers (Thomson 1992b). Carbyn (1989) speculated that this additional food stress drove coyotes to attempt predation on humans, particularly vulnerable children. This imperative might be expected to be highest in mothers, yet in our study incidents rarely

45 featured females, and adult females very infrequently. Still, although apparently very rare, there were occasional cases bearing a resemblance to those presented by Carbyn (1989).

Again, subadult males were the major sex-by-age class featured in incident reports at this time of year. It is possible

50 that they may contribute to feeding and defending pups, which in turn heightens food stress. However, their role in alloparental care is not clear and might be minimal compared with other classes of potential carers. Determining differences in alloparental care between the sex-by-age classes may

55 therefore offer insights into incident dynamics. Another possible but associated mechanism is that subadult males might become marginalised at this time of year in relation to food availability, which in turn drives them to seek food in riskier contexts. The potential role of hunger and natural/ artificial food availability in driving incident mechanics is deserving of more research.

\section{Distance between adults and children}

We determined that almost half of the incidents reported that involved children featured adults that were further than $5 \mathrm{~m}$ from children. We chose this distance to reflect the very high likelihood of an adult being able to quickly respond to a threat or attack. However, we noted that incidents occurred whether adults were this close to or, indeed, further away from children. An important, tentative (given the small sample size) distinction, though, relates to the severity of outcomes given the distance of adults from children. For example, in one tragic incident where children were definitely unsupervised by adults, a child died, so it is clear that dingoes can represent the most serious of risks to vulnerable people in some circumstances (Thompson et al. 2003). Other incidents in which medical assistance or hospitalisation of a child was required, though very few in number, also all occurred when adults were at a distance where they were unable to react before injury resulted.

Yet, our results also clearly show that dingoes rarely seriously injure even the most vulnerable of people, despite the opportunity to do so arising on occasion. Nor do they regularly seriously injure people more generally. In fact, large numbers of encounters, which are probably benign or positive in nature, go unreported (Burns and Howard 2003; Hytten and Burns 2007). This represents a clear conundrum in relation to managing conflict on the island, because the risk dingoes appear to pose to human safety is both almost always nominal, yet, in extreme cases, also potentially catastrophic. Given that latter cases are almost certain to involve children, coupled with the fact that no incidents resulting in serious injury involved adults that were $5 \mathrm{~m}$ or closer to children, a recommendation that adults remain within arm's reach to children at all possible times appears sound. And we would add that a critical component of management success and risk reduction pertains to whether some visitors are ignoring or misunderstanding the seriousness of warnings and, if so, why.

\section{Human activity and dingo behaviour}

It is not clear why a person or persons walking or running commonly feature in serious incidents. However, the 'chase' response in canids is well documented (Fox 1971; KolerMatznick 2002) and is a feature of canid behaviour in a variety of behavioural contexts including predation and play. While play behaviour directed at human beings is of management concern (Allen et al. 2012); arguably, predatory behaviour, would be of the greatest concern.

If dingo incidents on Fraser Island were largely driven by predatory motivations, including those where people were walking/running, then studies highlighting the proficiency of dingo predation in other contexts (Robertshaw and Harden 1985; Thomson 1992c; Allen 2015) suggest that many more serious incidents might be expected to have occurred. Given the right opportunities, small groups of dingoes are capable of killing relatively large numbers of prey animals in short order. For 
example, Shepherd (1981) observed a group of five dingoes kill 83 red kangaroos (mostly juveniles) near a waterhole over just a seven-week period. Thomson (1992a) suggested that the dingoes that he observed in the Fortescue river area were 5 amongst the largest in the country and this gave them an advantage in hunting large prey such as red kangaroos. The Fraser Island dingoes are almost as large as Thomson's dingoes, averaging $14.8 \mathrm{~kg}$ for females and $18 \mathrm{~kg}$ for males (Behrendorff et al. 2016). Presumably, this would make them equally

10 capable of attacking and killing humans, particularly children, but also adults in at least some circumstances. Again, however, our results demonstrate that outright attacks in which people are seriously injured are very rare. Linnell et al. (2002, 2003) stated that predatory behaviour directed at humans was not

15 normal behaviour for the average wolf and that most wolves do not see humans as prey. Arguably, the same can be said of dingoes.

Many cases may also fit an alternative explanation of play as a motivation (Corbett 1998; Allen et al. 2012; Allen et al.

20 2015; Appleby 2015a). Young dingoes, in particular, might be expected to engage in more play activity (compared with adults). Chasing and mock attacks are common features of play behaviour in canids (Bekoff 1974a, 1974b, 1995; Bauer and Smuts 2007), and, in turn, incidents that involve such

25 behaviour may be mistaken for similar behaviours exhibited in other contexts, such as predation. At present, we tentatively suspect that most incidents that feature young, solitary dingoes chasing or harassing adult humans while they are walking or running are probably not predatory and are more likely

30 playful, but we concede that more research is required to determine whether this is the case and under what circumstances behaviour might escalate.

\section{Feeding}

There were very few incidents in which anthropogenic feeding

35 could be directly attributed to human participants. However, this does not automatically mean that feeding does not play a role in incident dynamics. Because of the heavy penalties involved, the incidence of feeding may simply be voluntarily under-reported in incident reports. Or feeding might involve

40 other people not reporting. The potential association between feeding and higher incident rates is understandably the impetus for many wildlife management agencies attempting to restrict animals accessing anthropogenic food, including dingoes on Fraser Island (Corbett 1998; Allen et al. 2012; DEHP 2013).

45 Doing so may well reduce the prospect of serious incidents occurring, by reducing the prospect of interactions in the first place.

Overall, the role played by feeding in incident dynamics remains unclear. Unless, for example, an animal has learned that

50 acting aggressively towards humans results in their getting food, which we found no accounts of, any role must be more indirect. Behrendorff et al. (2016) recently found that the incidence of anthropogenic food in dingo scats has markedly declined in recent years, yet incidents, some serious, continue to occur. A

55 reduction in the prevalence of anthropogenic food in dingo diet is potentially encouraging in relation to limiting the prospect for interactions. However, while we strongly support management programs aimed at reducing access to anthropogenic food and discouraging close-quarter interactions more generally, we contend that the roles that feeding and habituation play in driving incident dynamics, at least for dingoes, remain uncertain and require further exploration.

\section{Conflicts of interest}

The authors confirm that there are no conflict of interests relating to this paper.

\section{Acknowledgements}

We thank Linda Behrendorff, Moyra McRae, Dan Novak and Dan Clifton from the Queensland Parks and Wildlife Service for their insights and support. Leisa Masterpon and Jason Edgar provided helpful comments on an early draft, for which we are very grateful. We thank Ben Allen for coordinating a variety of dingo-related projects, of which this was one. We are especially grateful to two anonymous reviewers, whose guidance greatly improved the manuscript. This project was funded by the Queensland Department of Science, Information Technology and Innovation. Ethical clearance for this research was obtained from the Griffith University Human Research Ethics Committee (clearance no. 2016/303). The authors declare no conflicts of interest.

\section{References}

Allen, B. L., and West, P. (2013). Influence of dingoes on sheep distribution in Australia. Australian Veterinary Journal 91, 261-267. doi:10.1111/ avj. 12075

Allen, B., Boswell, J. and Higginbottom, K. (2012) Fraser Island dingo management strategy review. Report to Department of Environment and Heritage Protection, Ecosure, West Burleigh.

Allen, B., Higginbottom, K., Bracks, J., Davies, N., and Baxter, G. (2015). Balancing dingo conservation with human safety on Fraser Island: the numerical and demographic effects of humane destruction of dingoes. Australasian Journal of Environmental Management 22, 197-215. doi:10.1080/14486563.2014.999134

Allen, L. R. (2015). Demographic and functional responses of wild dogs to poison baiting. Ecological Management \& Restoration 16, 58-66. doi:10.1111/emr.12138

Allen, L. R., and Sparkes, E. C. (2001). The effect of dingo control on sheep and beef cattle in Queensland. Journal of Applied Ecology 38, 76-87. doi:10.1046/j.1365-2664.2001.00569.x

Appleby, R. (2015a). Dingo-human conflict: attacks on humans. In 'The Dingo Debate: Origns, Behaviour and Conservation'. (Ed. B. Smith.) pp. 131-158. (CSIRO Publishing: Melbourne.)

Appleby, R. (2015b). Dingo-human conflict: attacks on livestock. In 'The Dingo Debate: Origns, Behaviour and Conservation'. (Ed. B. Smith.) pp. 103-122 (CSIRO Publishing: Melbourne.)

Appleby, R. G., and Jones, D. (2011). Analysis of a preliminary dingo capture-mark-recapture experiment on Fraser Island conducted by the Queensland Parks and Wildlife Service. Environmental Futures Centre, Griffith University.

Appleby, R. G., Burns, G. L., McBroom, J., and Jones, D. (2004). 'The Fraser Island Dingo Incident Database: A Preliminary Examination.' (Griffith University: Brisbane.)

Bauer, E. B., and Smuts, B. B. (2007). Cooperation and competition during dyadic play in domestic dogs, Canis familiaris. Animal Behaviour 73, 489-499. doi:10.1016/j.anbehav.2006.09.006

Behrendorff, L., and Allen, B. L. (2016). From den to dust: longevity of 55 three dingoes (Canis lupus dingo) on Fraser Island (K'gari). Australian Mammalogy 38, 256-260. doi:10.1071/AM16005 
Behrendorff, L., Leung, L. K.-P., McKinnon, A., Hanger, J., Belonje, G., Tapply, J., Jones, D., and Allen, B. L. (2016). Insects for breakfast and whales for dinner: the diet and body condition of dingoes on Fraser Island (K'gari). Scientific Reports 6, 23469. doi:10.1038/srep23469

5 Beier, P. (1991). Cougar attacks on humans in the United States and Canada. Wildlife Society Bulletin (1973-2006) 19, 403-412.

Bekoff, M. (1974a). Social play and play-soliciting by infant canids. American Zoologist 14, 323-340. doi:10.1093/icb/14.1.323

Bekoff, M. (1974b). Social play in coyotes, wolves, and dogs. Bioscience 24, 225-230. doi:10.2307/1296803

Bekoff, M. (1995). Play signals as punctuation: the structure of social play in canids. Behaviour 132, 419-429. doi:10.1163/156853995X00649

Breckwoldt, R. (1988). 'A Very Elegant Animal: the Dingo.' (Angus \& Robertson: Sydney.)

15 Burns, G. L., and Howard, P. (2003). When wildlife tourism goes wrong: a case study of stakeholder and management issues regarding dingoes on Fraser Island, Australia. Tourism Management 24, 699-712. doi:10.1016/ S0261-5177(03)00146-8

Carbyn, L. N. (1989). Coyote attacks on children in western North America. Wildlife Society Bulletin (1973-2006) 17, 444 446. doi:10.2307/3782710

Conover, M. R. (2001). 'Resolving Human-Wildlife Conflicts: the Science of Wildlife Damage Management.' (CRC Press: Florida, USA.)

Corbett, L. K. (1998). Management of dingoes on Fraser Island. ERA Environmental Services.

25 Corbett, L. K. (2001). 'The Dingo in Australia and Asia.' (JB Books Pty Ltd: Adelaide.)

Dalton, R. (2004). Wildlife attacks hinder conservation efforts. Nature 427, 385. doi: $10.1038 / 427385$ a

DEHP (2013). Fraser Island dingo conservation and risk management strategy. The Queensland State Government.

EPA/QPWS (2001). Fraser Island dingo management strategy. Environmental Protection Agency/Queensland Parks and Wildlife Service, Queensland Government.

EPA/QPWS (2006). Fraser Island dingo management strategy - review. Environmental Protection Agency/Queensland Parks and Wildlife Service, Queensland Government.

Fleming, P. J. S., Corbett, L. K., Harden, R., and Thomson, P. C. (2001). Managing the impacts of dingoes and other wild dogs. Bureau of Rural Sciences, Canberra.

40 Fox, M. (1971). 'Behaviour of Wolves, Dogs and Related Canids.' (Jonathan Cape: London.)

Geist, V. (2011). Wildlife habituation: advances in understanding and management application. Human-Wildlife Interactions 5, 9-12.

Gilsdorf, J. M., Hygnstrom, S. E., and VerCauteren, K. C. (2002). Use of frightening devices in wildlife damage management. Integrated Pest Management Reviews 7, 29-45. doi:10.1023/A:1025760032566

Herrero, S. (1970). Human injury inflicted by grizzly bears. Science $\mathbf{1 7 0}$, 593-598. doi:10.1126/science.170.3958.593

Herrero, S. (2002). 'Bear Attacks: their Causes and Avoidance.' (The Lyons Press: Guilford, CT.)

Herrero, S., and Fleck, S. (1990). Injury to people inflicted by black, grizzly or polar bears: recent trends and new insights. Bears: Their Biology and Management 8, 25-32. doi: $10.2307 / 3872900$

Herrero, S., and Higgins, A. (1999). Human injuries inflicted by bears in British Columbia: 1960-97. Ursus 11, 209-218.

Herrero, S., and Higgins, A. (2003). Human injuries inflicted by bears in Alberta: 1960-98. Ursus 14, 44-54.

Herrero, S., Higgins, A., Cardoza, J. E., Hajduk, L. I., and Smith, T. S. (2011). Fatal attacks by American black bear on people: 1900-2009. Journal of Wildlife Management 75, 596-603. doi:10.1002/jwmg.72

Hopkins, J. B.III, Herrero, S., Shideler, R. T., Gunther, K. A., Schwartz, C. C., and Kalinowski, S. T. (2010). A proposed lexicon of terms and concepts for human-bear management in North America. Ursus 21, 154-168. doi:10.2192/URSUS-D-10-00005.1
Hytten, K. F., and Burns, G. L. (2007). Deconstructing dingo management on Fraser Island, Queensland: the significance of social constructionism for effective wildlife management. Australasian Journal of Environmental Management 14, 48-62. doi:10.1080/14486563.2007.9725149

Inskip, C., and Zimmermann, A. (2009). Human-felid conflict: a review of 5 patterns and priorities worldwide. Oryx 43, 18-34. doi:10.1017/ S003060530899030X

Jope, K. L. (1985). Implications of grizzly bear habituation to hikers. Wildlife Society Bulletin (1973-2006) 13, 32-37. doi:10.2307/3781944

Koler-Matznick, J. (2002). The origin of the dog revisited. Anthrozoos 15, 1 98-118. doi:10.2752/089279302786992595

Linnell, J. D. C., Andersen, R., Andersone, Z., Balciauskas, L., Blanco, J. C., Boitani, L., Brainerd, S. M., Breitenmoser, U., Kojola, I., and Liberg, O. (2002). The fear of wolves: a review of wolf attacks on people. NINA Oppdragsmelding 731: $65 \mathrm{pp}$.

Linnell, J. D., Solberg, E. J., Brainerd, S., Liberg, O., Sand, H., Wabakken, P., and Kojola, I. (2003). Is the fear of wolves justified? A Fennoscandian perspective. Acta Zoologica Lituanica 13, 34-40. doi:10.1080/ 13921657.2003.10512541

Martin, P., and Bateson, P. (1986). 'Measuring Behaviour.' (Cambridge University Press: Cambridge.)

Massei, G., Quy, R. J., Gurney, J., and Cowan, D. P. (2010). Can translocations be used to mitigate human-wildlife conflicts? Wildlife Research 37, 428-439. doi:10.1071/WR08179

Mazur, R. L. (2010). Does aversive conditioning reduce human-black bear conflict? Journal of Wildlife Management 74, 48-54. doi:10.2193/2008163

McCullough, D. R. (1982). Behavior, bears, and humans. Wildlife Society Bulletin (1973-2006) 10, 27-33. doi:10.2307/3781798

McNay, M. E. (2002). Wolf-human interactions in Alaska and Canada: a review of the case history. Wildlife Society Bulletin 30, 831-843.

O’Neill, A. J., Cairns, K. M., Kaplan, G., and Healy, E. (2017). Managing dingoes on Fraser Island: culling, conflict, and an alternative. Pacific Conservation Biology 23, 4-14. doi:10.1071/PC16026

Peine, J. D. (2001). Nuisance bears in communities: strategies to reduce conflict. Human Dimensions of Wildlife 6, 223-237. doi:10.1080/ 108712001753461301

Penteriani, V., del Mar Delgado, M., Pinchera, F., Naves, J., Fernández-Gil, A., Kojola, I., Härkönen, S., Norberg, H., Frank, J., and Fedriani, J. M. (2016). Human behaviour can trigger large carnivore attacks in developed countries. Scientific Reports 6, doi:10.1038/srep20552

QPWS (2015). Be dingo safe. Flyer, Queensland Parks and Wildlife Service/ Department of National Parks, Sport and Racing, Queensland Government. Available at: http://www.nprsr.qld.gov.au/parks/fraser/pdf/ be-dingo-safe-flyer.pdf.

Rajpurohit, K. S. (1999). Child lifting: wolves in Hazaribagh, India. AmbioJournal of Human Environment Research and Management 28, 162-166.

Reiter, D. K., Brunson, M. W., and Schmidt, R. H. (1999). Public attitudes toward wildlife damage management and policy. Wildlife Society Bulletin 27, 746-758.

Robertshaw, J., and Harden, R. (1985). The ecology of the dingo in northeastern New South Wales. 2. Diet. Wildlife Research 12, 39-50. doi:10.1071/WR9850039

Rogers, L. L., and Mansfield, S. A. (2011). Misconceptions about black bears: a response to Geist (2011). Human-Wildlife Interactions 5, 173-196.

Schmidt, R. H., and Timm, R. M. (2007). Bad dogs: why do coyotes and other canids become unruly? In '12th Wildlife Damage Management Conference'. (Eds D. L. Nolte, W. M. Arjo, and D. H. Stalman.) pp. 287-302. (University of Nebraska: Lincoln, NE.)

Shepherd, N. C. (1981). Predation of red kangaroos, Macropus rufus, by the dingo, Canis familiaris dingo (Blumenbach) in north-western New South Wales. Wildlife Research 8, 255-262. doi:10.1071/ WR9810255 
Smith, B. (2015). Biology and behaviour of the dingo. In 'The Dingo Debate: Origins, Behaviour and Conservation'. (Ed. B. Smith.) pp. 25-53. (CSIRO Publishing: Melbourne.)

Smith, B., and Appleby, R. (2015). Forging a new future for the Australian dingo. In 'The Dingo Debate: Origins, Behaviour and Conservation'. (Ed. B. Smith.) pp. 301-315. (CSIRO Publishing: Melbourne.)

Smith, B., Flavel, M., and Simpson, B. (2016). Quantification of salivary cortisol from captive dingoes (Canis dingo) in relation to age, sex, and breeding season: implications for captive management. Australian Mammalogy 38, 21-28. doi:10.1071/AM15017

Thompson, J., Shirreffs, L., and McPhail, I. (2003). Dingoes on Fraser Islandtourism dream or management nightmare. Human Dimensions of Wildlife 8, 37-47. doi:10.1080/10871200390180136

Thomson, P. C. (1992a). The behavioural ecology of dingoes in north-western 15 Australia. I. The Fortescue River Study Area and details of captured dingoes. Wildlife Research 19, 509-518. doi:10.1071/WR9920509
Thomson, P. C. (1992b). The behavioural ecology of dingoes in north-western Australia. II. Activity patterns, breeding season and pup rearing. Wildlife Research 19, 519-530. doi:10.1071/WR9920519

Thomson, P. C. (1992c). The behavioural ecology of dingoes in north-western Australia. III. Hunting and feeding behaviour, and diet. Wildlife Research 19, 531-541. doi:10.1071/WR9920531

Timm, R. M., Baker, R. O., Bennett, J. R., and Coolahan, C. C. (2004). Coyote attacks: an increasing suburban problem. In 'Transactions of the North American Wildlife and Natural Resources Conference'. (Eds R. M. Timm, and W. P. Gorenzel.) pp. 67-88. (Wildlife Management 10 Institute: Washington, DC.)

White, L. A., and Gehrt, S. D. (2009). Coyote attacks on humans in the United States and Canada. Human Dimensions of Wildlife 14, 419-432. doi:10.1080/10871200903055326

Whittaker, D., and Knight, R. L. (1998). Understanding wildlife responses to 15 humans. Wildlife Society Bulletin (1973-2006) 26, 312-317.

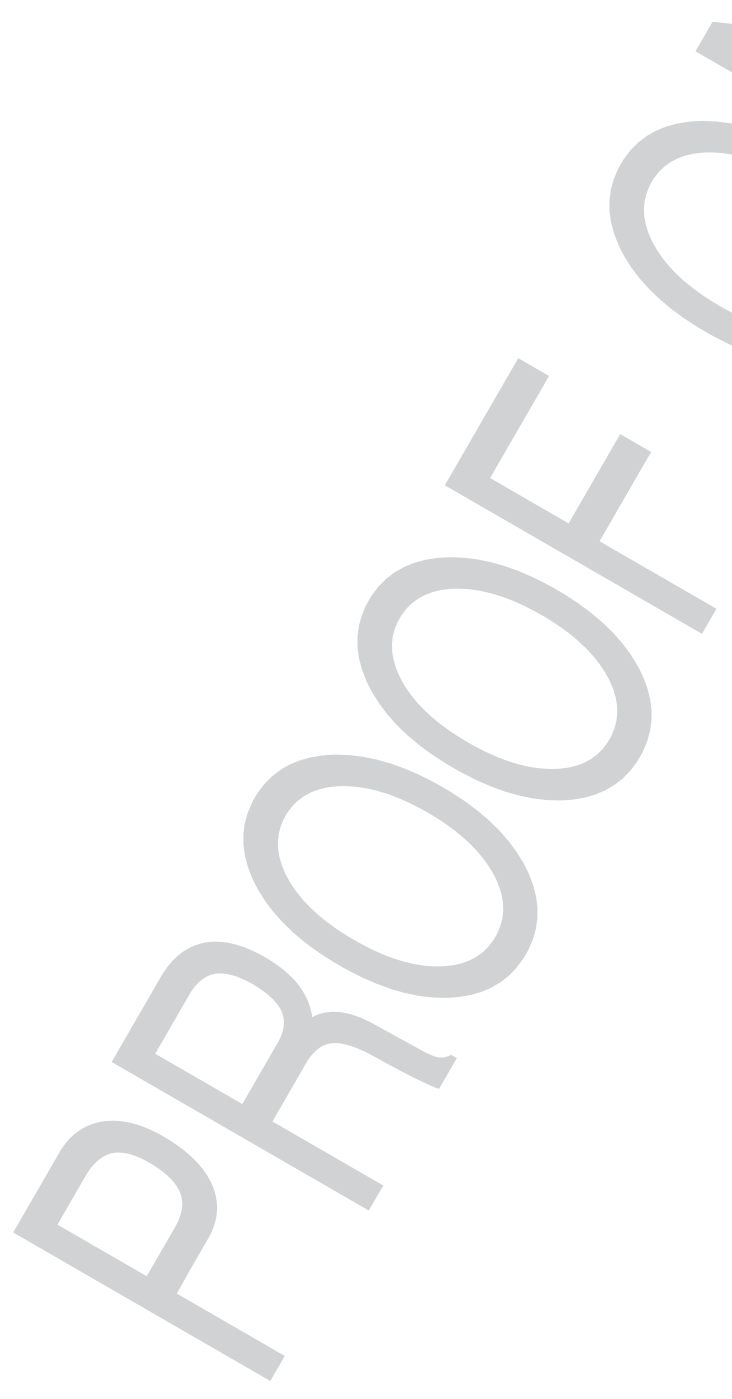

